\title{
Inspissated bile syndrome in an infant with citrin deficiency and congenital anomalies of the biliary tract and esophagus: Identification and pathogenicity analysis of a novel $S L C 25 A 13$ mutation with incomplete penetrance
}

\author{
HAN-SHI ZENG ${ }^{1 *}$, SHU-TAO ZHAO ${ }^{*}$, MEI DENG ${ }^{1}$, ZHAN-HUI ZHANG $^{2}$, \\ XIANG-RAN CAI ${ }^{3}$, FENG-PING $\mathrm{CHEN}^{4}$ and YUAN-ZONG SONG ${ }^{1}$ \\ ${ }^{1}$ Department of Pediatrics, ${ }^{2}$ Central Laboratory, ${ }^{3}$ Medical Imaging Center, and ${ }^{4}$ Department of Laboratory Science, \\ The First Affiliated Hospital, Jinan University, Guangzhou, Guangdong 510630, P.R. China
}

Received May 23, 2014; Accepted September 5, 2014

DOI: $10.3892 /$ ijmm.2014.1929

\begin{abstract}
Biallelic mutations of the SLC25A13 gene result in citrin deficiency (CD) in humans. Neonatal intrahepatic cholestasis caused by citrin deficiency (NICCD) is the major CD phenotype in pediatrics; however, knowledge on its genotypic and phenotypic characteristics remains limited. The present study aimed to explore novel molecular and clinical characteristics of $\mathrm{CD}$. An infant suspected to have NICCD as well as her parents were enrolled as the research subjects. SLC25A13 mutations were investigated using various methods, including cDNA cloning and sequencing. The pathogenicity of a novel mutation was analyzed bioinformatically and functionally with a yeast model. Both the infant and her father were heterozygous for $\mathrm{c} .2 \mathrm{~T}>\mathrm{C}$ and $\mathrm{c} .790 \mathrm{G}>\mathrm{A}$, while the mother was only a c.2T $>$ C carrier. The novel c.790G $>$ A mutation proved bioinformatically and functionally pathogenic. The infant had esophageal atresia and an accessory hepatic duct, along with bile plug formation confirmed by laparoscopic surgery.
\end{abstract}

Correspondence to: Professor Yuan-Zong Song, Department of Pediatrics, The First Affiliated Hospital, Jinan University, No. 613, Huangpu Da Dao Xi, Tianhe, Guangzhou, Guangdong 501630, P.R. China

E-mail: songyuanzong@vip.tom.com

*Contributed equally

Abbreviations: $\mathrm{CD}$, citrin deficiency; NICCD, neonatal intrahepatic cholestasis caused by citrin deficiency; CTLN2, adult-onset type 2 citrullinemia; FTTDCD, failure to thrive and dyslipidemia caused by citrin deficiency; AGC2, aspartate/glutamate carrier isoform 2; GGT, gamma-glutamyl transpeptidase; Dbil, direct bilirubin; TBA, total bile acid

Key words: citrin deficiency, inspissated bile syndrome, esophageal atresia, functional analysis
However, the father seemed to be healthy thus far. The findings of the present study enrich the genotypic and phenotypic characteristics of CD patients, and provided clinical and molecular evidence suggesting the possible non-penetrance of $S L C 25 \mathrm{~A} 13$ mutations and the likely involvement of this gene in primitive foregut development during early embryonic life.

\section{Introduction}

The SLC25A13 gene on chromosome 7q21.3 was cloned, whilst its protein product, CITRIN, was designated in 1999 by Kobayashi et al (1). This breakthrough finding opened up a new research field on citrin deficiency (CD) and laid the foundation for subsequent investigation into this autosomal recessive disorder. Subsequently, citrin was found to be the liver-type aspartate/glutamate carrier isoform 2 (AGC2) $(2,3)$. The laboratory and clinical characteristics of this $\mathrm{CD}$, whether molecular (4-12), biochemical $(13,14)$, medical imaging (15), hepatohistological (16-18), metabolomic $(19,20)$, behavioral (21), therapeutic (22-26) or epidemiological (27-31), have been increasingly depicted, while patients with $\mathrm{CD}$ have been diagnosed not only in Asia (32-42), but also in Europe (43-46) and North America (47-49). Currently, CD has developed into a worldwide panethnic disease entity encompassing at least three age-dependent clinical phenotypes, i.e. neonatal intrahepatic cholestasis caused by citrin deficiency (NICCD) in neonates or infants, adult-onset type 2 citrullinemia (CTLN2) in adolescents and adults, as well as failure to thrive and dyslipidemia caused by citrin deficiency (FTTDCD), which was recently suggested to be a novel CD phenotype between NICCD and CTLN2 $(7,11,12,19,50,51)$.

Although considerable laboratory and clinical progress has been made in $\mathrm{CD}$ research, the genotypic and phenotypic characteristics of this disease entity remain far from being completely clarified. To date, a total of 84 deleterious mutations of the SLC25A13 gene have been reported $(11,12,30,52-54)$, constituting valuable molecular evidence for the definite diagnosis of patients with $\mathrm{CD}$. However, the pathogenicity of the majority of missense mutations was based on conventional 
bioinformatics evidence and studies on their direct functional effects are rather limited $(10,12)$. Moreover, all phenotypic, therapeutic and prognostic knowledge on patients with CD has been gained through the clinical management of such patients, both pediatric and adult, and knowledge on the effects of SLC25A13 mutations on CD fetuses remains limited (55), constituting a novel issue of perinatal medicine. In the present study, an infant with NICCD was diagnosed, who harbored a novel deleterious SLC25A13 mutation and demonstrated inspissated bile syndrome (IBS) along with multiple congenital anomalies of the digestive system. We herein report the molecular and clinical characteristics of this case of NICCD.

\section{Subjects and methods}

Subjects and ethics. The research subjects in the present study were a female infant (C0218) suspected to have NICCD and her parents. The clinical findings of this family were described as a case report. The majority of the data were collected at our clinical practice or from the laboratory and imaging databases at our own hospital, with partial biochemical or imaging results from the medical records in another hospital, which were provided by the parents of the patient at the time of her referral.

This study was carried out after written informed consent was obtained from the parents of the infant prior to their enrollment in the present study. For screening analysis of the novel mutation, 60 used blood samples (with 120 SLC25A13 alleles) for health examinations were collected as the controls. This study was approved by the Committee for Medical Ethics, the First Affiliated Hospital, Jinan University, Guangzhou, China, adhering to the World Medical Association Declaration of Helsinki (WMADH 2008), which was adopted by the 59th WMA General Assembly, Seoul, Korea, in October 2008.

Molecular diagnosis of CD. Genomic DNA was extracted from peripheral blood samples collected from the subjects. Four high-frequency mutations of the SLC25A13 gene, i.e., c.851_854delGTAT, c.1638_1660dup, c.615+5G>A and IVS16ins3kb, were screened by PCR/long and accurate (LA)PCR and PCR-restriction fragment length polymorphism (RFLP) analysis. Subsequently, all 18 exons and their flanking genomic sequences were amplified by PCR/LA-PCR, and the amplified products were then sequenced, as described in our previous studies $(7-9,11,15)$.

RT-PCR, cDNA cloning and sequencing. As previously described by our group $(9,11)$, EDTA anticoagulant peripheral blood samples were collected, the lymphocytes were isolated with lymphocyte separation medium (LSM, MP) and then homogenized immediately in RNAiso Plus (Takara Bio Inc., Otsu, Japan) to extract the total mRNA following the manufacturer's instructions. Subsequently, the SLC25A13 transcripts were reverse-transcribed and amplified by PCR, and the purified products were cloned into the pSIMPLE-18 EcoRV/ BAP Vector (Takara Bio Inc.) and transformed into DH5 $\alpha$ Escherichia coli competent cells. To examine the co-segregation of the $2 S L C 25 A 13$ variations detected in the family, only the cDNA clones containing exons 1 and 8 together were selected for further sequencing analysis, since the 2 variations occurred in these 2 exons, respectively. The sequencing results of the cDNA clones were aligned with the SLC25A13 mRNA sequence to judge the parental origins of the 2 variations.

Screening of the novel missense variation in controls. A nested PCR-RFLP procedure was performed in the present study for the screening for the novel missense variation in the control individuals. The nucleotide sequences of the forward and reverse primers were as follows: 5'-TCACTCATTCCAGT GCCTTG-3' (IVS6F) and 5'-CAATGCCGCAAAGGCAA CTG-3' (IVS8B) in the first PCR; and 5'-GAGTTTGTTC TGGCAGCACAG-3' (Ex8F) and 5'-TATTTCAGTATAG CCTTCAGTTTGG-3' (Ex8R) in the second. The temperature profile was $94^{\circ} \mathrm{C}$ for 5 min followed by 40 cycles $(20$ cycles in the second PCR) of $94^{\circ} \mathrm{C}$ for $30 \mathrm{sec}, 59^{\circ} \mathrm{C}$ for $40 \mathrm{sec}$ and $72^{\circ} \mathrm{C}$ for $1.0 \mathrm{~min}$, and a final extension step at $72^{\circ} \mathrm{C}$ for $10 \mathrm{~min}$. The restriction endonuclease for RFLP analysis was Hpy188I (New England Biolabs Inc., Ipswich, MA, USA). For frequency calculation of the variation, the mutated allele number was divided by the total allele number of the SLC25A13 gene in all controls and then the quotient was amplified by $100 \%$.

Bioinformatics analysis. The conservative property of the amino acid affected by the novel missense mutation was surveyed as described in our previous publication (11). Briefly, using a comparative alignment software of Genetyx ${ }^{\circledR}$ version 7.1 (Genetyx Co., Tokyo, Japan), the amino acid sequences of human citrin and aralar were aligned with those in the homologous proteins from 10 different eukaryotic species, including chimpanzee, dog, mouse, rat, chicken, Xenopus tropicalis, macaque, Caenorhabditis elegans, opossum and cow. The amino acid sequences of the homologous proteins were collected from ENSEMBL at http://www.ensembl.org/ index.html. Moreover, 2 online tools, MutationTaster (http:// mutationtaster.org/MutationTaster/index.html) and PolyPhen-2 (http://genetics.bwh.harvard.edu/pph2/), were used in this study to evaluate the pathogenic potential of the novel missense mutation. In the first software, a probability value close to 1 indicates a high 'security' of the prediction and in the second software used, the mutation with a probabilistic score $>0.85$ is classified as 'probably damaging', while a score $>0.15$ is classified as 'possibly damaging', as recently described (12).

Functional effects of the novel missense mutation. A yeast model with a disruption of the $\mathrm{agcl}$ gene, which is highly homologous to human SLC25A13, was applied in the present study to evaluate the functional effects of the novel missense mutation. The diploid agcl-disrupted yeast strain, BYagcl $\Delta$, was the same as the one used in our previous publication (12). The normal citrin-encoding cDNA sequence was amplified and recombined into the expression vector, pYX212 (Novagen Inc., Madison, WI, USA), to form the plasmid, pYX212-citrin. The novel missense mutation was introduced into the wild-type cDNA by overlap-extension PCR, and the generated variants were cloned into pYX212 to constitute the plasmid pYX212mutant. Subsequently, transformation of the BYagc1 $\Delta$ strain with the empty plasmid pYX212 (vector), pYX212-mutant and pYX212-citrin control (citrin) was carried out, and the transformed strains were cultured in SA medium with acetate as the unique carbon source. The growth abilities of the transformed 
Table I. Dynamic alterations of the biochemical indices in the infant with citrin deficiency.

\begin{tabular}{lccccccccccccc}
\hline $\begin{array}{l}\text { Biochemical } \\
\text { indices }\end{array}$ & $3.3 \mathrm{M}$ & $3.5 \mathrm{M}$ & $4.0 \mathrm{M}$ & $4.3 \mathrm{M}$ & $4.5 \mathrm{M}^{\mathrm{a}}$ & $4.6 \mathrm{M}$ & $4.7 \mathrm{M}$ & $4.8 \mathrm{M}$ & $5.0 \mathrm{M}$ & $5.5 \mathrm{M}$ & $5.8 \mathrm{M}$ & $7.0 \mathrm{M}^{\mathrm{b}}$ & $11 \mathrm{M}$ \\
\hline ALT $(5-40 \mathrm{U} / \mathrm{l})$ & 49 & 44 & 100 & 138 & 198 & 99 & 137 & 83 & 58 & 40 & 55 & 36 & 27 \\
AST $(5-40 \mathrm{U} / \mathrm{l})$ & 66 & 58 & 88 & 118 & 124 & 75 & 113 & 62 & 50 & 37 & 67 & 37 & 45 \\
GGT $(8-50 \mathrm{U} / \mathrm{l})$ & 444 & 411 & 537 & 532 & 388 & 313 & 465 & 508 & - & 364 & 134 & 318 & 34 \\
ALP $(20-500 \mathrm{U} / \mathrm{l})$ & 618 & 588 & 1133 & 1209 & 1332 & 1011 & 1428 & 944 & 643 & 174 & 426 & 420 & 399 \\
TP $(60.0-83.0 \mathrm{~g} / \mathrm{l})$ & 56.9 & 54.9 & 61.2 & 56.1 & 50.0 & 56.8 & 60.8 & 68.5 & 73.5 & - & 61.6 & 68.7 & 68.6 \\
Alb $(35.0-55.0 \mathrm{~g} / \mathrm{l})$ & 40.2 & 39.7 & 41.7 & 39.4 & 34.6 & 40.5 & 43.5 & 45.4 & 49.0 & - & 45.5 & 50.0 & 51.1 \\
Glb $(20.0-30.0 \mathrm{~g} / \mathrm{l})$ & 16.7 & 15.2 & 19.5 & 16.7 & 15.4 & 16.3 & 17.3 & 23.1 & 24.5 & - & 16.1 & 18.7 & 17.5 \\
Tbil $(2-19 \mu \mathrm{mol} / \mathrm{l})$ & 67.7 & 59.2 & 123.6 & 149.8 & 204.5 & 148.3 & 135.9 & 67.3 & 45.4 & 20.3 & 13.2 & 3.9 & 5.5 \\
Dbil $(0-6 \mu \mathrm{mol} / \mathrm{l})$ & 53.8 & 48.7 & 96.3 & 118.4 & 161.6 & 120.1 & 110.8 & 57.4 & 40.1 & 13.0 & 9.4 & 1.8 & 1.4 \\
Ibil $(2.56-20.9 \mu \mathrm{mol} / \mathrm{l})$ & 13.9 & 10.5 & 27.3 & 31.4 & 42.9 & 28.2 & 25.1 & 9.9 & 5.3 & 7.3 & 3.8 & 2.1 & 4.1 \\
TBA $(0-10 \mu \mathrm{mol} / \mathrm{l})$ & 157.5 & 152.8 & 135.1 & 112.3 & 173.3 & 26.6 & 26.9 & 5.5 & 4.7 & 49.33 & 8.7 & 7.3 & 2.1 \\
\hline
\end{tabular}

M, months (age of infant). ${ }^{a}$ Time at which laparoscopic surgery was performed, and ${ }^{b}$ time of referral to our hospital. ALT, alanine transaminase; AST, aspartate transaminase; GGT, gamma-glutamyl transpeptidase; ALP, alkaline phosphatase; TP, total protein; Alb, albumin; Glb, globulin; Tbil, total bilirubin; Dbil, direct bilirubin; Ibil, indirect bilirubin; TBA, total bile acid.

strains were examined after $96 \mathrm{~h}$ of culture by measuring the $\mathrm{OD}_{600}$, and the data were analyzed with one-way ANOVA followed by the Bonferroni method to compare the differences in the mean values among the different groups, with a value of $\mathrm{P}<0.05$ considered to indicate a statistically significant difference. All raw data were logarithmically transformed in the case of non-homogeneity of variance prior to statistical comparison.

\section{Results}

Case report. A 7-month-old female infant was referred to our hospital due to prolonged jaundice for approximately 4 months and growth retardation for 1.5 months. Her jaundice (yellow skin and sclera) drew the attention of her parents at the age of 3.3 months. A liver function test at the local hospital revealed elevated cholestatic indices, including gamma-glutamyl transpeptidase (GGT), direct bilirubin (Dbil) and total bile acid (TBA) (Table I). Due to the prolonged jaundice and unresolved laboratory abnormalities, the infant was referred to another hospital at the age of 4 months, where magnetic resonance cholangiopancreatography revealed the dilatation of common hepatic and bile ducts. Laparoscopy was thus performed when the infant was aged 4.5 months, and an intraoperative cholangiography displayed biliary tree dilatation and filling defect in the common bile duct, along with an accessory hepatic duct (AHD) joining the cystic duct (Fig. 1A). A cholecystectomy was subsequently performed, an intrabiliary thick plug in the color of dark green was removed, and bile duct irrigation and choledochostomy with T-tube drainage was carried out. Pathological analysis of the plug confirmed the diagnosis of inspissated bile syndrome (IBS). Thereafter, the infant's jaundice subsided and the laboratory indices gradually improved (Table I); the infant was discharged at the age of 5 months. Half a month later, nevertheless, a physical exami- nation revealed that her body weight was $5.34 \mathrm{~kg}$ (-3.6 SD), her length was $59 \mathrm{~cm}(-3.2 \mathrm{SD})$ and her head circumference was $39 \mathrm{~cm}(-2.5 \mathrm{SD})$. Another anthropometric test at the age of 6 months revealed a weight of $6.0 \mathrm{~kg}(-2.5 \mathrm{SD})$ and a length of $62.0 \mathrm{~cm}(-2.2 \mathrm{SD})$. The growth retardation continued in the following month, and the infant was referred to our hospital at the age of 7 months for further evaluation, following the removal of the drainage T-tube.

The infant was born to a non-consanguineous couple after 37 weeks of uneventful gestation with a birth weight of $2.25 \mathrm{~kg}$. On the first day after birth, the infant was admitted to hospital due to vomiting and respiratory distress. Contrast imaging of the upper digestive tract revealed the existence of esophageal atresia (EA) (Fig. 1C), which was then resolved by a gastroesophagostomy under general anesthesia. The couple had experienced 2 pregnancies prior to this one, but both were aborted in the first trimester. Both parents appeared healthy, without any clinical symptoms or signs of CTLN2. There was no known family history of any genetic disease.

Physical examination at referral revealed a weight of $6.25 \mathrm{~kg}$ (-2.6 SD), a length of $63.0 \mathrm{~cm}$ (-3.3 SD) and a head circumference of $42 \mathrm{~cm}$ (-1.0 SD). There was no dysmorphic appearance, only a slightly chubby face. There was no evidence of jaundice (yellow skin and sclera) and there were no visible petechiae or ecchymoses. No pallor or cyanosis of the lips were observed. There was no tachypnea or dyspnea, and no stridor, wheezes, crackles or crepitus could be heard on auscultation of the both lungs. The heart sounds were normal without audible murmurs or arrhythmia. Upon abdominal inspection, no dilated veins or abdominal distention were observed. The liver was palpated with a soft edge $2 \mathrm{~cm}$ below the right costal margin in the midclavicular line. Her spleen was not palpable. A neurological examination revealed slightly reduced muscle tone. There was no neck stiffness, knee reflex was normal and there was no positivity for Brudzinski's or Kernig's sign. 


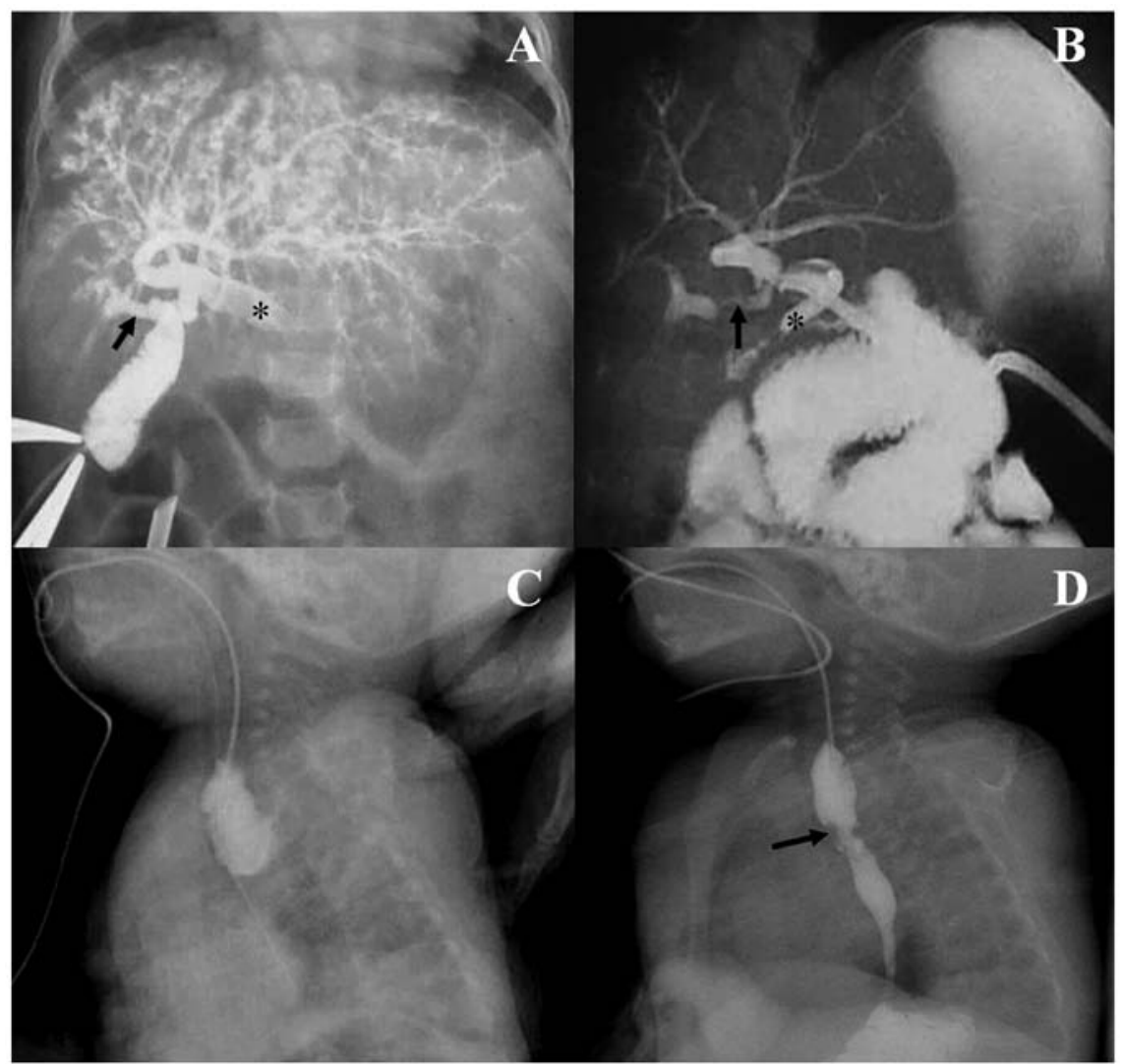

Figure 1. Cholangiography via punctured gallbladder and esophageal contrast radiography. Note the filling defect in the common bile duct (asterisk) and the dilated upstream biliary tract without contrast flow into the duodenum, and the accessory right hepatic duct (arrow) joining the cystic duct (A). A postoperative contrast study (B) via the T-tube placed into the common bile duct (asterisk) displayed a right bile duct stricture (arrow) where the gallbladder had been surgically removed. Note the free contrast passage into the duodenum. Esophageal contrast radiography (C) before gastroesophagostomy showed obvious dilatation of the upper esophagus, without contrast flow into the trachea, lower esophagus or stomach, while postoperative contrast radiography (D) displayed the contrast flow through a mild annular stricture (arrow) between the upper and middle esophagus.

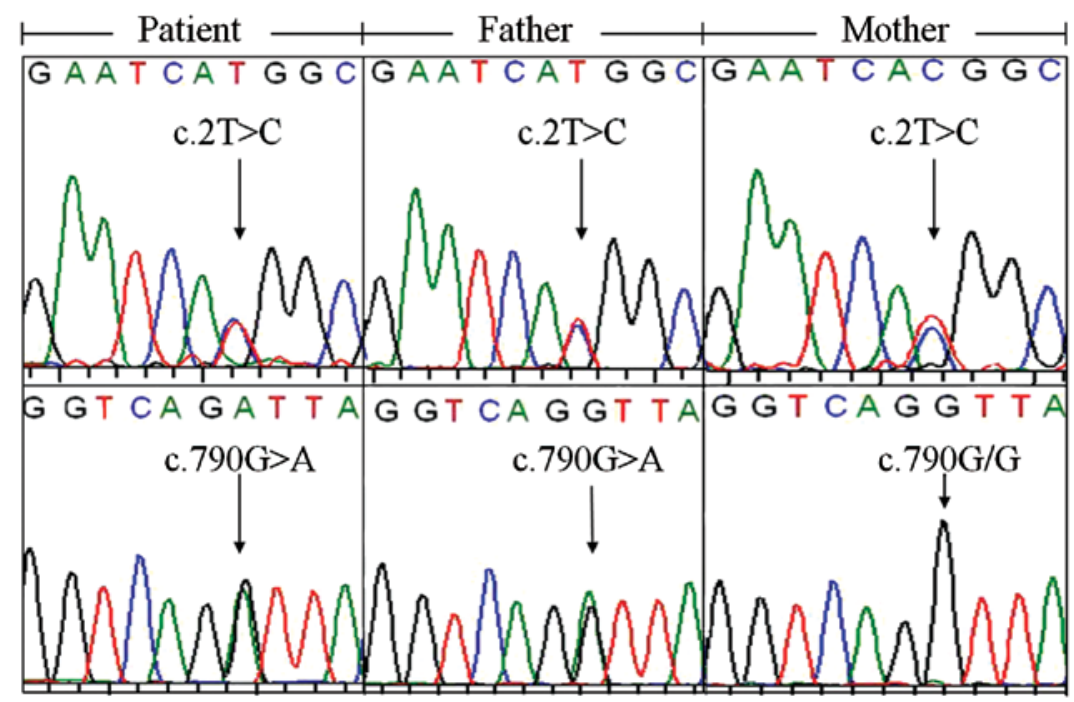

Figure 2. SLC25A13 gene variations in the family unveiled by direct DNA sequencing. The patient and her father both harbored the c.2T>C and c.790G $>\mathrm{A}$ (p.V264I) variations, while the mother was only a carrier of the former variation.

Following biochemical analysis, no abnormal liver function index was observed, although the serum GGT level was elevated, suggesting the existence of cholestasis, as shown in Table I. Taking into consideration her prolonged jaundice, growth retardation and chubby face, and the 2 first-trimester miscarriages of her mother, SLC25A13 gene analysis was performed on the family to evaluate the possibility of a diagnosis of CD. A lactose-free and MCT-enriched therapeutic 


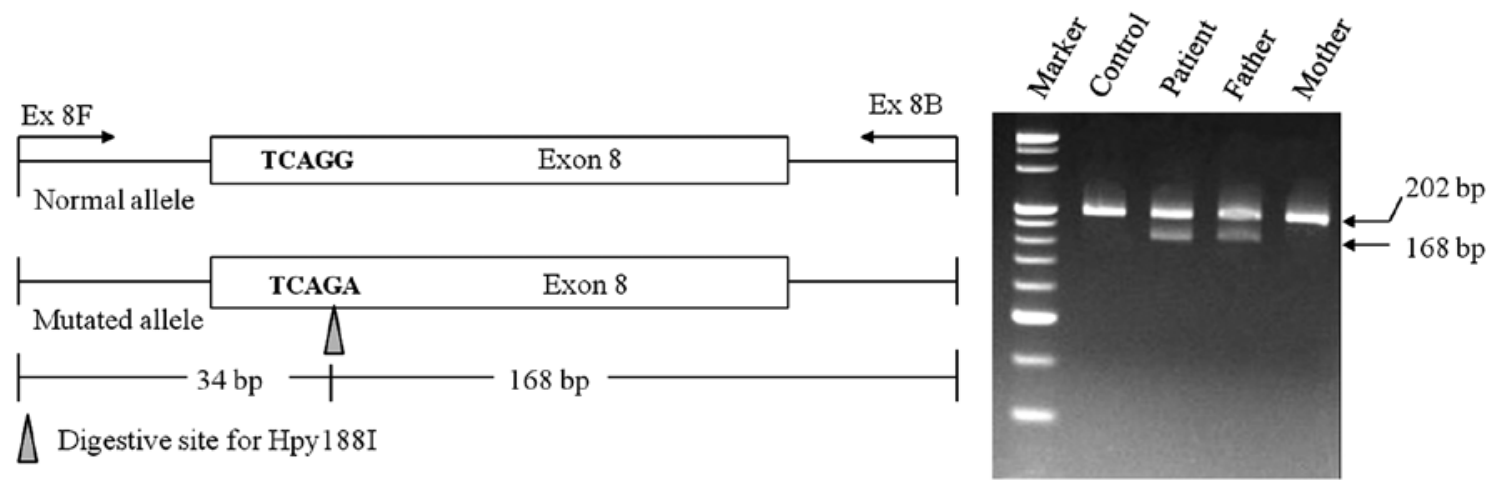

Figure 3. Nested PCR-RFLP protocol for the screening of the c.790G >A(p.V264I) variation. (Left panel) Schematic diagram of the enzymatic digestive protocol. The variation generated a digestive site for the enzyme Hpy188I, producing 2 fragments of 34 and $168 \mathrm{bp}$. PCR amplification of the normal allele gave rise to an expected product of $202 \mathrm{bp}$. (Right panel) Representative gel electrophoresis for the PCR products digested with Hpyl88I, showing a band of $202 \mathrm{bp}$ from the normal allele, and another band of $168 \mathrm{bp}$ due to the variation. Note that the patient and her father were both heterozygous for the variation, while the mother was not.

$\begin{array}{ll} & \\ & \\ \text { Human Citrin } & \text { 228NNMELIRKIYSTLAGTRKDVEVTKEEFVLAAQKFGQVTPMEVDILFQLADLYEPRGRMTL287 } \\ \text { Human Alarar } & \text { 227NNMELVRKIYSTLAGTRKDVEVTKEEFAQSAIRYGQVTPLEIDILYQLADLYNASGRLTL286 } \\ \text { Chimpanzee } & \text { 228NNMELIRKIYSTLAGTRKDVEVTKEEFVLAAQKFGQVTPMEVDILFQLADLYEPRGRTL287 } \\ \text { Dog } & \text { 228NNMELIRKIYSTLAGNRKDVEVTKEEFVLAAQKFGQVTPMEVDILFQLADLYEPRGGIL287 } \\ \text { Mouse } & \text { 223NNMELIRKIYSTLAGNRKDVEVTKEEFALAAQKFGQVTPMEVDILFQLADLYEPRGRTL282 } \\ \text { Rat } & \text { 223NNMELIRKIYSTLAGSRKDVEVTKEEFALAAQKFGQVTPMEVDILFQADLYEPRGRTL282 } \\ \text { Chicken } & \text { 223NNMELIRKIYSTLAGNRKDVEVTKEEFVLAAQKFGQVTPMEVDILFQLADLYEPRGRTL282 } \\ \text { X. tropicalis } & \text { 227NNMELIRKIYSTLAGNKKDLEVTKEEFVLAAQRFGQVTPMEVDILFQLADLYEPRGRTL286 } \\ \text { Macaque } & \text { 42NNMELIRKIYSTLAGNRKVVEVTKEEFVLAAQKFGQTPMEVDILFRLADLYEPRGRTL101 } \\ \text { C. elegans } & \text { 268AKMELIKRVYVTTRGNLDIEMTKEEFLHAIQSYTQVTPYEVEILFHLSELNHP-GRKTL326 } \\ \text { Opossum } & \text { 204TNTETMKRIYHTLAGPGKDVEVTKEEFALAAQKFGQVTPMEVNILFQLADLHEPRGRLTL263 } \\ \text { Cow } & \text { 157NNMELIRKIYSTLAGNRKDVEVTKEEFVLAAQKFGQVTPMEVDILFQLADLYEPRGRTL216 }\end{array}$

Figure 4. Comparative alignment of the amino acid sequences of the homologous proteins. The mutation p.V264I affected an amino acid highly conservative in all the 12 homologous proteins from 11 eukaryotic species including human, chimpanzee, dog, mouse, rat, chicken, Xenopus tropicalis, macaque, Caenorhabditis elegans, opossum and cow.

formula was subsequently introduced, while a diet rich in protein and lipids was also encouraged. A clinical followingup 4 months later revealed that the weight of the infant was $7.9 \mathrm{~kg}(-1.6 \mathrm{SD})$, her length was $70 \mathrm{~cm}(-1.5 \mathrm{SD})$ and her head circumference was $44 \mathrm{~cm}(-0.8 \mathrm{SD})$, along with a marked improvement (complete recovery) of the cholestatic indices, GGT, TBA and Dbil (Table I).

SLC25A13 genotypic characteristics of the family. Highfrequency mutation screening did not reveal any SLC25A13 mutation. However, direct DNA sequencing revealed that both the infant and her father harbored c.2T $>C$ and c.790G $>A$ (p.V264I) variations, while the mother was only a carrier of c. $2 \mathrm{~T}>\mathrm{C}$ (Fig. 2). To the best of our knowledge, c.790G $>\mathrm{A}$ is a novel SLC25A13 variation that has not been previously reported. Following SLC25A13 cDNA cloning analysis, from a total of 27 clones from the infant, 7 were found to harbor c.2T>C, another 18 carried c.790G $>$ A, 1 had neither, and the remaining clone had both variations. Analysis of the cDNA clones from the father revealed similar characteristics. The total 29 cDNA clones consisted of 9 clones with c. $2 \mathrm{~T}>\mathrm{C}$, 13 with c.790G $>$ A, 3 with neither, and 4 with both variations. These findings clearly indicated that the 2 variations were both biallelic, not only in the infant displaying clinical characteristics, but also in her father who did not show any symptoms or signs of $\mathrm{CD}$ to date.

Bioinformatic evidence of the pathogenicity of the novel mutation. Using the newly-developed nest PCR-RFLP protocol (Fig. 3), c.790G >A (p.V264I) was screened in 60 control samples and no carrier was found, indicating a frequency of $<1 \%$. The comparative alignment of the amino acid sequences of the homologous protein in a diversity of species (Fig. 4) documented the highly conservative property of the valine at codon 264 affected by this mutation. The probability value of $>0.9999$ upon MutationTaster analysis strongly indicated its deleterious nature, but according to the results produced by Polyphen-2 analysis, this mutation was predicted to be benign with a score as low as 0.001 . This discrepancy necessitated conducting functional analysis for this novel missense mutation.

Effect of the novel mutation on the AGC2 function of citrin protein. As illustrated in Fig. 5, the growth ability of the BYagcl $\Delta$ yeast transformed with the mutant plasmid (p.V264I) was significantly reduced $(\mathrm{P}<0.01)$ in comparison with that 


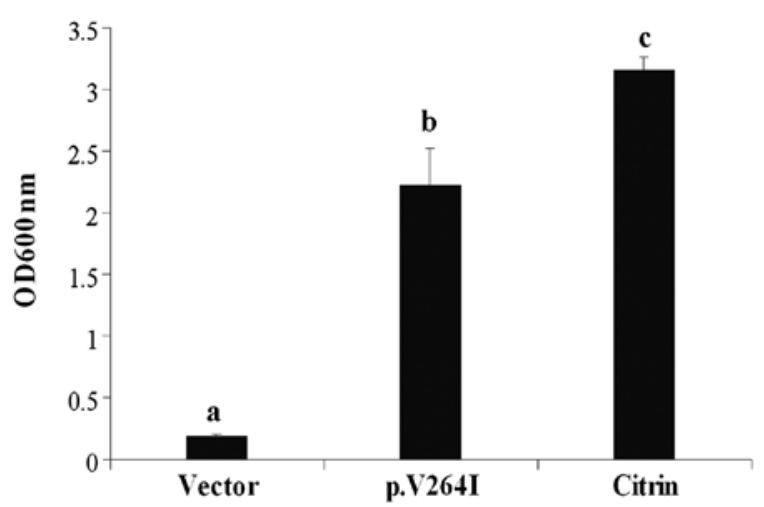

Figure 5. Effect of the novel c.790G $>$ A(p.V264I) mutation on the AGC2 function of citrin protein. The agcl $\Delta$ yeast strains transformed with empty plasmid pYX212 (vector), pYX212-mutant (p.V264I) and pYX212-CITRIN control (citrin) were cultured in SA medium for $96 \mathrm{~h}$, and their growth abilities were examined by measuring $\mathrm{OD}_{600 \mathrm{~nm}}$. The results are the means $\pm \mathrm{SD}$ of 6 repeated experiments, and different letters above the bars indicated a statistically significant difference $(\mathrm{P}<0.01)$.

transformed with the plasmid pYX212-citrin (citrin). However, when compared with the empty plasmid group (vector), the growth ability in the mutant group (p.V264I) was still higher $(\mathrm{P}<0.01)$. These findings indicated that the p.V264I mutation reduced, but did not eliminate the AGC2 function of citrin protein.

\section{Discussion}

In previous studies, the c. $2 \mathrm{~T}>\mathrm{C}$ variation frequency was found to be $3.0 \%(6 / 200)$ in a Chinese (9), and approximately $2.8 \%$ $(85 / 3074)$ in a Thai population (31), both suggesting that it may be a single-nucleotide polymorphism (SNP) of the SLC25A13 gene. This initiation codon variation gave rise to a citrin molecule lacking the first 34 amino acid residues, and this truncated protein lost the ability to localize within the mitochondrial membrane, thereby leading to an almost complete loss of AGC2 function (10). Although the frequency of this deleterious SNP has been proven to be rather high, a homozygous variation (a patient with CD) has yet to be identified. A possible explanation for this issue is the homozygote lethality. In the present study, the two spontaneous miscarriages of the mother in the first trimester may reflect the high pathogenicity of this SNP. It was very likely that the two aborted fetuses (possibly both with homozygous SNP) could not survive through an uneventful pregnancy. As regards the c.790G $>$ A mutation, in addition to the bioinformatic evidence supporting its disease-causing characteristic, the functional analysis in this study provided direct eukaryotic evidence further solidifying its pathogenicity. However, this missense mutation caused the reduction, but not the elimination of AGC2 function of citrin protein, as illustrated in Fig. 5. This is the most likely explanation for the survival of this infant through the entire pregnancy, and her delivery as a full term baby. This novel c.790G $>$ A mutation, along with the c.2T $>\mathrm{C}$ variation, constituted reliable diagnostic evidence for NICCD in the infant, and further expanded the mutation spectrum of the SLC25A13 gene.

The term IBS, also known as bile plug syndrome, was used to indicate patients with prolonged jaundice in whom normal extrahepatic bile ducts containing inspissated bile were found at surgery for presumed extrahepatic biliary atresia (56). Although cholestasis has been reported as a characteristic histological characteristic of NICCD (17), such a large bile plug causing obstruction of the common bile duct as in this infant has not been reported previously in patients with NICCD. The contributing factors for IBS included $\mathrm{Rh}$ and ABO incompatibility, blood transfusion, parenteral nutrition in pre-term infants, diuretic medication, bowel dysfunction and disseminated intravascular coagulation (57). None of these factors was found in this infant, and CD may be a very likely contributing etiology for her IBS. Actually, canalicular bile secretion involves a series of ATP-binding cassette transporters as export pumps for bile salts and other organic solutes (58), and among these, the bile salt export pump (BSEP), a pump noteworthy in particular, transports bile acids across the apical membrane and constitutes the major determinant and driving force for the generation of bile flow (59). Since CD causes energy shortage in the liver $(12,24)$, the function of these transporters, including BSEP, would thereby be affected inevitably in this infant with NICCD, causing deficit of the major driving force, disturbing her generation of bile flow, giving rise to intra- and extrahepatic cholestasis, and finally resulting in IBS formation.

Accessory bile ducts are rare congenital anomalies of the primitive foregut bud during the development of the biliary tract before 5 weeks of gestational age; apart from their importance to the radiologist and to the biliary and hepatic transplant surgeon, these anomalies may be associated with congenital lesions elsewhere (60). In the present study, the infant with NICCD with AHD also suffered from EA, another malformation originated from the division of the primitive foregut into ventral respiratory and dorsal esophageal parts during the 4 th week of embryonic life (61). Although the underlying mechanisms remain unknown, EA has been recognized a multifactorial complex disease with the involvement of genetic and environmental factors, and has been reported to be associated with some single-gene disorders, such as Feingold syndrome, CHARGE, anophthalmia-oesophagealgenital (AEG) and Opitz G syndrome $(61,62)$. To the best of our knowledge, congenital anomalies of the digestive system in patients with CD have been rarely reported, although a Chinese infant with NICCD with congenital biliary atresia, confirmed by abdominal laparoscopy and liver biopsy, was previoulsy reported (54). In the present study, we reported the concurrent existence of AHD and EA in an infant with NICCD. These findings suggest that the SLC25A13 mutation may be an additional contributing genetic factor leading to congenital anomalies of the primitive foregut during the early stage of fetal development, although more molecular, embryonic and histological evidence is required in order to address this issue.

Non-penetrance refers to the lack of clinical signs and symptoms in genetically affected individuals. This phenomenon is not uncommon, not only in Mendelian disorders inherited as autosomal dominant traits $(63,64)$, but also in some autosomal recessive diseases, such as Brown-Vialetto-Van Laere syndrome (65) and Wolfram syndrome (66). Whether or not $\mathrm{CD}$ penetrance is complete has remained an unresolved issue for years (27). However, there have been several reports on adult individuals harboring the biallelic but non-penetrant 
mutations of the SLC25A13 gene, at least at the age these individuals were when these mutations were reported. Two adult siblings had been definitely diagnosed as being homozygous for the c.851_854del4 mutation, one demonstrating the typical clinical and laboratory manifestations of CTLN2, while the other did not (67). In addition, a girl with the SLC25A13 genotype c.851_854del4/c.1799_1800ins A displayed characteristics of NICCD, but her mother heterozygous for the mutations c.1799_1800insA and IVS16ins3kb did not display any symptoms of CTLN2, as it recently demonstrated by a Japanese group (68). In the present study, we reported similar findings. The lack of CTLN2 phenotypic characteristics in the father, who had the same genotype as that of the infant with NICCD, lent further support to the concept that CD penetrance may be incomplete, and suggested the existence of other environmental, genetic or epigenetic factors that may modulate the onset of CTLN2.

In conclusion, in this study, we reported two individuals in the same family both harboring the same biallelic variations, but demonstrating markedly different phenotypic features. The infant had IBS and multiple anomalies of the digestive system, while the father appeared healthy. Bioinformatically and functionally, the c.790G $>$ A variation proved to be a novel pathogenic mutation of the SLC25A13 gene. These findings further enrich the clinical and molecular spectrum of NICCD, and suggest the existence of $\mathrm{CD}$ non-penetrance and the possible involvement of $S L C 25 A 13$ in primitive foregut development during early embryonic life.

\section{Acknowledgements}

The authors would like to thank all research subjects for their kind cooperation in providing blood samples and clinical data. The present study was financially supported by grants from the Innovation Fund of Jinan University (No. 21612430) and the National Natural Science Foundation of China (Nos. 81070279 and 81270957).

\section{References}

1. Kobayashi K, Sinasac DS, Iijima M, et al: The gene mutated in adult-onset type II citrullinaemia encodes a putative mitochondrial carrier protein. Nat Genet 22: 159-163, 1999.

2. Palmieri F: The mitochondrial transporter family SLC25: identification, properties and physiopathology. Mol Aspects Med 34: 465-484, 2013

3. Palmieri F: Mitochondrial transporters of the SLC25 family and associated diseases: a review. J Inherit Metab Dis 37: 565-575, 2014.

4. Tokuhara D, Iijima M, Tamamori A, et al: Novel diagnostic approach to citrin deficiency: analysis of citrin protein in lymphocytes. Mol Genet Metab 90: 30-36, 2007.

5. Xing YZ, Qiu WJ, Ye J, et al: Studies on the clinical manifestation and SLC25A13 gene mutation of Chinese patients with neonatal intrahepatic cholestasis caused by citrin deficiency. Zhonghua Yi Xue Yi Chuan Xue Za Zhi 27: 180-185, 2010 (In Chinese).

6. Fu HY, Zhang SR, Wang XH, et al: The mutation spectrum of the SLC25A13 gene in Chinese infants with intrahepatic cholestasis and aminoacidemia. J Gastroenterol 46: 510-518, 2011.

7. Song YZ, Deng M, Chen FP, et al: Genotypic and phenotypic features of citrin deficiency: five-year experience in a Chinese pediatric center. Int J Mol Med 28: 33-40, 2011.

8. Lin WX, Zhang ZH, Deng M, Cai XR and Song YZ: Multiple ovarian antral follicles in a preterm infant with neonatal intrahepatic cholestasis caused by citrin deficiency: a clinical, genetic and transcriptional analysis. Gene 505: 269-275, 2012.
9. Zhang ZH, Lin WX, Deng M, Zhao XJ and Song YZ: Molecular analysis of SLC25A13 gene in human peripheral blood lymphocytes: marked transcript diversity, and the feasibility of cDNA cloning as a diagnostic tool for citrin deficiency. Gene 511: 227-234, 2012.

10. Wongkittichote P, Tungpradabkul S, Wattanasirichaigoon D and Jensen LT: Prediction of the functional effect of novel SLC $25 A 13$ variants using a $S$. cerevisiae model of AGC2 deficiency. J Inherit Metab Dis 36: 821-830, 2013.

11. Song YZ, Zhang ZH, Lin WX, et al: SLC25A13 gene analysis in citrin deficiency: sixteen novel mutations in East Asian patients, and the mutation distribution in a large pediatric cohort in China. PLoS One 8: e74544, 2013.

12. Zhang ZH, Lin WX, Deng M, et al: Clinical, molecular and functional investigation on an infant with neonatal intrahepatic cholestasis caused by citrin deficiency (NICCD). PLoS One 9: e89267, 2014.

13. Nagasaka H, Okano Y, Tsukahara H, et al: Sustaining hypercitrullinemia, hypercholesterolemia and augmented oxidative stress in Japanese children with aspartate/glutamate carrier isoform 2-citrin-deficiency even during the silent period. Mol Genet Metab 97: 21-26, 2009.

14. Wang JS, Wang XH, Zheng YJ, et al: Biochemical characteristics of neonatal cholestasis induced by citrin deficiency. World J Gastroenterol 18: 5601-5607, 2012.

15. Song YZ,Li BX, Chen FP, et al: Neonatal intrahepatic cholestasis caused by citrin deficiency: clinical and laboratory investigation of 13 subjects in mainland of China. Dig Liver Dis 41: 683-689, 2009.

16. Komatsu M, Yazaki M, Tanaka N, et al: Citrin deficiency as a cause of chronic liver disorder mimicking non-alcoholic fatty liver disease. J Hepatol 49: 810-820, 2008.

17. Kimura A, Kage M, Nagata I, et al: Histological findings in the livers of patients with neonatal intrahepatic cholestasis caused by citrin deficiency. Hepatol Res 40: 295-303, 2010.

18. Jiang GY, Cheng ZM and Liu KS: Neonatal intrahepatic cholestasis caused by citrin deficiency: a histopathologic study of 10 cases. Zhonghua Bing Li Xue Za Zhi 41: 452-455, 2012 (In Chinese).

19. Saheki T, Inoue $\mathrm{K}$, Ono $\mathrm{H}$, et al: Metabolomic analysis reveals hepatic metabolite perturbations in citrin/mitochondrial glycerol-3-phosphate dehydrogenase double-knockout mice, a model of human citrin deficiency. Mol Genet Metab 104: 492-500, 2011.

20. Kuhara T, Ohse M, Inoue Y and Cooper AJ: A GC/MS-based metabolomic approach for diagnosing citrin deficiency. Anal Bioanal Chem 400: 1881-1894, 2011.

21. Okano Y, Kobayashi K, Ihara K, et al: Fatigue and quality of life in citrin deficiency during adaptation and compensation stage. Mol Genet Metab 109: 9-13, 2013.

22. Shigeta T, Kasahara M, Kimura T, et al: Liver transplantation for an infant with neonatal intrahepatic cholestasis caused by citrin deficiency using heterozygote living donor. Pediatr Transplant 14: E86-E88, 2010.

23. Yazaki M, Ikeda S, Kobayashi K and Saheki T: Therapeutic approaches for patients with adult-onset type II citrullinemia (CTLN2): effectiveness of treatment with low-carbohydrate diet and sodium pyruvate. Rinsho Shinkeigaku 50: 844-847, 2010 (In Japanese).

24. Hayasaka K, Numakura C, Toyota K and Kimura T: Treatment with lactose (galactose)-restricted and medium-chain triglyceride-supplemented formula for neonatal intrahepatic cholestasis caused by citrin deficiency. JIMD Rep 2: 37-44, 2012.

25. Saheki T, Inoue K, Ono H, et al: Effects of supplementation on food intake, body weight and hepatic metabolites in the citrin/mitochondrial glycerol-3-phosphate dehydrogenase double-knockout mouse model of human citrin deficiency. Mol Genet Metab 107: 322-329, 2012.

26. Yazaki M, Kinoshita M, Ogawa S, et al: A 73-year-old patient with adult-onset type II citrullinemia successfully treated by sodium pyruvate and arginine. Clin Neurol Neurosurg 115: 1542-1545, 2013

27. Lu YB, Kobayashi K, Ushikai M, et al: Frequency and distribution in East Asia of 12 mutations identified in the SLC25A13 gene of Japanese patients with citrin deficiency. J Hum Genet 50: 338-346, 2005.

28. Kikuchi A, Arai-Ichinoi N, Sakamoto O, et al: Simple and rapid genetic testing for citrin deficiency by screening 11 prevalent mutations in SLC25A13. Mol Genet Metab 105: 553-558, 2012. 
29. Treepongkaruna $S$, Jitraruch $S$, Kodcharin $P$, et al: Neonata intrahepatic cholestasis caused by citrin deficiency: prevalence and SLC25A13 mutations among Thai infants. BMC Gastroenterol 12: 141, 2012.

30. Chen R, Wang XH, Fu HY, et al: Different regional distribution of SLC25A13 mutations in Chinese patients with neonatal intrahepatic cholestasis. World J Gastroenterol 19: 4545-4551, 2013.

31. Wongkittichote P, Sukasem C, Kikuchi A, et al: Screening of SLC25A13 mutation in the Thai population. World J Gastroenterol 19: 7735-7742, 2013.

32. Luder AS, Tabata A, Iijima M, Kobayashi $\mathrm{K}$ and Mandel $\mathrm{H}$ : Citrullinaemia type 2 outside East Asia: Israeli experience. J Inherit Metab Dis 29: S59, 2006.

33. Yeh JN, Jeng YM, Chen HL, Ni YH, Hwu WL and Chang MH: Hepatic steatosis and neonatal intrahepatic cholestasis caused by citrin deficiency (NICCD) in Taiwanese infants. J Pediatr 148 642-646, 2006.

34. Ohura T, Kobayashi, K, Tazawa Y, et al: Clinical pictures of 75 patients with neonatal intrahepatic cholestasis caused by citrin deficiency (NICCD). J Inherit Metab Dis 30: 139-144, 2007.

35. Ko JM, Kim GH, Kim JH, et al: Six cases of citrin deficiency in Korea. Int J Mol Med 20: 809-815, 2007.

36. Chew HB, Ngu LH, Zabedah MY, et al: Neonatal intrahepatic cholestasis associated with citrin deficiency (NICCD): a case series of 11 Malaysian patients. J Inherit Metab Dis 33: S489-S495, 2010.

37. Lee BH, Jin HY, Kim GH, Choi JH and Yoo HW: Nonalcoholic fatty liver disease in 2 siblings with adult-onset type II citrullinemia. J Pediatr Gastroenterol Nutr 50: 682-685, 2010.

38. Ngu HL, Zabedah MY and Kobayashi K: Neonatal intrahepatic cholestasis caused by citrin deficiency (NICCD) in three Malay children. Malays J Pathol 32: 53-57, 2010.

39. Thong MK, Boey CC, Sheng JS, Ushikai M and Kobayashi K: Neonatal intrahepatic cholestasis caused by citrin deficiency in two Malaysian siblings: outcome at one year of life. Singapore Med J 51: e12-e14, 2010.

40. Lin JT, Hsiao KJ, Chen CY, et al: High resolution melting analysis for the detection of SLC25A13 gene mutations in Taiwan. Clin Chim Acta 412: 460-465, 2011.

41. Chen ST, Su YN, Ni YH, et al: Diagnosis of neonatal intrahepatic cholestasis caused by citrin deficiency using high-resolution melting analysis and a clinical scoring system. J Pediatr 161: 626-631, 2012.

42. Takahashi Y, Koyama S, Tanaka H, et al: An elderly Japanese patient with adult-onset type II citrullinemia with a novel D493G mutation in the SLC25A13 gene. Intern Med 51:2131-2134, 2012

43. Hutchin T, Preece MA, Kobayashi K, et al: Neonatal intrahepatic cholestasis caused by citrin deficiency (NICCD) in an European patient. J Inherit Metab Dis 29: S112, 2006

44. Hutchin T, Preece MA, Hendriksz C, et al: Neonatal intrahepatic cholestasis caused by citrin deficiency (NICCD) as a cause of liver disease in infants in the UK. J Inherit Metab Dis 32: S151-S155, 2009.

45. Fiermonte G, Parisi G, Martinelli D, et al: A new Caucasian case of neonatal intrahepatic cholestasis caused by citrin deficiency (NICCD): a clinical, molecular, and functional study. Mol Genet Metab 104: 501-506, 2011.

46. Vitoria I, Dalmau J, Ribes C, et al: Citrin deficiency in a Romanian child living in Spain highlights the worldwide distribution of this defect and illustrates the value of nutritional therapy. Mol Genet Metab 110: 181-183, 2013.

47. Dimmock D, Kobayashi K, Iijima M, et al: Citrin deficiency: a novel cause of failure to thrive that responds to a high-protein, low-carbohydrate diet. Pediatrics 119: e773-e777, 2007.

48. Dimmock D, Maranda B, Dionisi-Vici C, et al: Citrin deficiency, a perplexing global disorder. Mol Genet Metab 96: 44-49, 2009.

49. Wong LJ, Dimmock D, Geraghty MT, et al: Utility of oligonucleotide array-based comparative genomic hybridization for detection of target gene deletions. Clin Chem 54: 1141-1148, 2008 .
50. Kobayashi K, Saheki T and Song YZ: Citrin Deficiency. In: GeneReviews ${ }^{\mathrm{TM}}$ (Internet). Pagon RA, Bird TD, Dolan CR, Stephens K and Adam MP (eds). Seattle (WA): University of Washington, Seattle; 1993-2005 Sep 16 (updated 2012 Jan 05).

51. Woo HI, Park HD and Lee YW: Molecular genetics of citrullinemia types I and II. Clin Chim Acta 431: 1-8, 2014

52. Tabata A, Sheng JS, Ushikai M, et al: Identification of 13 novel mutations including a retrotransposal insertion in $S L C 25 \mathrm{~A} 13$ gene and frequency of 30 mutations found in patients with citrin deficiency. J Hum Genet 53: 534-545, 2008.

53. Wen P, Wang G, Chen Z, et al: Clinical investigation and mutation analysis of a child with citrin deficiency complicated with purpura, convulsive seizures and methioninemia. Zhonghua Yi Xue Yi Chuan Xue Za Zhi 30: 649-653, 2013 (In Chinese).

54. Tong F, Yang JB, Huang XL, Zhou XL and Yang RL: A case of neonatal intrahepatic cholestasis caused by citrin deficiency complicated with congenital biliary atresia. Zhonghua Er Ke Za Zhi 51: 863-865, 2013 (In Chinese).

55. Zhao XJ, Tang XM, Zha QB, et al: Prenatal diagnosis of citrin deficiency in a Chinese family with a fatal proband. Tohoku J Exp Med 225: 273-276, 2011.

56. Desmet VJ and Roskams TA: Cholestatic syndromes of infancy and childhood. In: Hepatology, a textbook of liver disease. Zakim D and Boyer TD (eds). 4th edition. Saunders, Philadelphia, pp1481-1536, 2003.

57. Heaton ND, Davenport $M$ and Howard ER: Intraluminal biliary obstruction. Arch Dis Child 66: 1395-1398, 1991.

58. Boyer JL: Bile formation and secretion. Compr Physiol 3: 1035-1078, 2013

59. Suchy FJ and Ananthanarayanan M: Bile salt excretory pump: biology and pathobiology. J Pediatr Gastroenterol Nutr 43: S10-S16, 2006.

60. Sherlock S and Dooley J: Cysts and congenital biliary abnormalities. In: Diseases of the liver and biliary system. Sherlock $S$ Dooley J (eds ). 11th edition. Victoria (Australia): Blackwell Publishing Asia, pp583-596, 2005.

61. de Jong EM, Felix JF, de Klein A and Tibboel D: Etiology of esophageal atresia and tracheoesophageal fistula: 'mind the gap'. Curr Gastroenterol Rep 12: 215-222, 2010.

62. Felix JF, de Jong EM, Torfs CP, de Klein A, Rottier RJ and Tibboel D: Genetic and environmental factors in the etiology of esophageal atresia and/or tracheoesophageal fistula: an overview of the current concepts. Birth Defects Res A Clin Mol Teratol 85: 747-754, 2009

63. Dworschak GC, Draaken M, Hilger A, et al: An incompletely penetrant novel MAFB (p.Ser56Phe) variant in autosomal dominant multicentric carpotarsal osteolysis syndrome. Int J Mol Med 32: 174-178, 2013.

64. Jéru I, Charmion S, Cochet E, et al: Involvement of the same TNFR1 residue in mendelian and multifactorial inflammatory disorders. PLoS One 8: e69757, 2013.

65. Dezfouli MA, Yadegari S, Nafissi S and Elahi E: Four novel C20orf54 mutations identified in Brown-Vialetto-Van Laere syndrome patients. J Hum Genet 57: 613-617, 2012.

66. Boutzios G, Livadas S, Marinakis E, Opie N, Economou F and Diamanti-Kandarakis E: Endocrine and metabolic aspects of the Wolfram syndrome. Endocrine 40: 10-13, 2011.

67. Imamura Y, Kobayashi K, Shibatou T, et al: Effectiveness of carbohydrate-restricted diet and arginine granules therapy for adult-onset type II citrullinemia: a case report of siblings showing homozygous SLC25A13 mutation with and without the disease. Hepatol Res 26: 68-72, 2003.

68. Yagi M, Kosunoki N, Lee T, Kikuchi A, Kure S and Takeshima Y: A Japanese family with citrin deficiency: a daughter with NICCD and a mother without symptoms of CTLN2. The 3rd Asian Congress for Inherited Metabolic Diseases (ACIMD)/The 55th Annual Meeting of The Japanese Society for inherited metabolic diseases (JSIMD): Program Book, Japan, 2013 Nov 27-29. Chiba: P149. 